\title{
Microstructure and Strength of Diffusion Bonded 2014 AA Alloys Using Copper Interlayer
}

\author{
Abass Ali Saleh \\ Department of Materials Engineering, College of Engineering, Mustansiriyah University, Baghdad, Iraq \\ Email: abassaltememi@yahoo.com
}

How to cite this paper: Saleh, A.A. (2019) Microstructure and Strength of Diffusion Bonded 2014 AA Alloys Using Copper Interlayer. Open Journal of Applied Sciences, 9, 342-353.

https://doi.org/10.4236/ojapps.2019.95028

Received: April 3, 2019

Accepted: May 12, 2019

Published: May 15, 2019

Copyright $\odot 2019$ by author(s) and Scientific Research Publishing Inc. This work is licensed under the Creative Commons Attribution International License (CC BY 4.0).

http://creativecommons.org/licenses/by/4.0/

\section{c) (i) Open Access}

\begin{abstract}
The major awkwardness when joining AA2014 lies in the presence of creation of oxide films and brittle intermetallic in the bond region. However, diffusion bonding can be used to join these alloys without much difficulty. This paper reveals the characterization of diffusion connection of aluminum alloy AA 2014 with and without applying copper powder. Joining was achieved in vacuum up to $\left(1 \times 10^{-5} \mathrm{mbar}\right)$ by means of vacuum system. Aluminum alloy AA2014 samples were done as cylinder form and interlayer thickness was equal $100 \mu \mathrm{m}$, under joining conditions of $\left(325^{\circ} \mathrm{C}-475^{\circ} \mathrm{C}\right)$ and $4 \mathrm{MPa}$ and period of (1 hour). The ultimate strength was found equal to $188.36 \mathrm{MPa}$. Bonding joint was examined using light microscope, (SEM) with (EDS) for determining microstructure and depth of diffusion and microhardness was also used at connection zone. XRD outcomes display that the main intermetallic compound phase formula was $\mathrm{Al}_{2} \mathrm{C}$. The maximum depth of diffusion obtained was $19.1 \mu \mathrm{m}$.
\end{abstract}

\section{Keywords}

2014 AA Alloys, Diffusion Bonding, Microstructure

\section{Introduction}

In numerous engineering scopes, $\mathrm{Al}$ and its alloys are widely employed as suitable materials for constructions wanted to be lightened. AA2014 alloy is vital for army vehicle and aerospace requests [1]. Aluminum and alloy's welding by conventional procedures give rise to various flaws, for instance deformation, air holes, and cracks, so there was a specific welding method essential to prevent or reduce these flaws. Product necessities in the aerospace, aircraft, electronics, 
missile, nuclear, and commercial arenas have brought about several novel and demanding service conditions. To encounter the stringent necessities of these demanding operations, it is not solitary required to develop novel material, but it is imperative to find new means to make them into valuable engineering components. Solid phase joining process is one of such fabrication techniques [2]. Diffusion joining is one type of solid-state welding procedure used for dissimilar and similar materials by means of interlayers or in the absence of utilizing interlayers [3]. The joining by means of interlayers is employed to recover the bonding joint. The interlayer can be utilized as powder, sheet, and foil or by deposit coating procedures. There is several usefulness of utilizing appropriate interlayer such rising the strength of the joining joint, reducing the development of weak intermetallic at joining region [4]. The goodness of a joint is based on its strength. To fetch the maximum strength, it is significant to control the relevant process parameters (temperature, pressure and interlayer) entirely. Consequently, it is very significant to control and choose the welding process parameters [5]. All previous studies were restrictive to the evaluation of the diffusion parameters influence and microstructure at the interface of the diffusion bond. But, limited researches have considered the effect the interlayers function on the diffusion bonding joint and the influence of interlayer on the same materials. In the present study, the effect of bonding variables: temperature pressure and pure copper powder interlayer on the joint strength was investigated, also evaluating the intermetallic compound that may be formed during bonding.

\section{Experimental Procedure}

\subsection{Materials}

In this investigation, the base metals used was AA2014. Pure copper powder with particle size of $14-25 \mu \mathrm{m}$ was utilized as interlayer. The chemical composition and physical properties of base metals and interlayer are tabulated in Table 1 , Table 2 respectively.

\subsection{Test Materials and Specimen Preparation}

The aluminum alloy AA2014 was received as rods with $15 \mathrm{~mm}$ diameter. Then,

Table 1. The weight percentage of the chemical compositions.

\begin{tabular}{cccccccccccc}
\hline Alloy & $\mathrm{Si}$ & $\mathrm{Fe}$ & $\mathrm{Cu}$ & $\mathrm{Mn}$ & $\mathrm{Mg}$ & $\mathrm{Cr}$ & $\mathrm{Zn}$ & $\mathrm{Ti}$ & $\mathrm{Pb}$ & $\mathrm{In}$ & $\mathrm{Al}$ \\
\hline 2014 & 0.81 & 0.7 & 4.4 & 0.8 & 0.5 & 0.1 & 0.25 & 0.15 & - & - & Bal. \\
Cupowder & - & - & 99.80 & - & - & - & - & - & 0.125 & 0.075 & - \\
\hline
\end{tabular}

Table 2. Some physical properties base metals and copper interlayer.

\begin{tabular}{cccc}
\hline Alloy & Purity $\%$ & Liner Thermal expansion $\left(\mu \mathrm{m} /{ }^{\circ} \mathrm{C}\right)$ & Density $\mathrm{g} / \mathrm{cm}^{3}$ \\
\hline AA2014 & & 23 & 2.8 \\
Cu powder & 99.8 & 17 & 8.96 \\
\hline
\end{tabular}


cut into $35 \mathrm{~mm}$ length of cylinder portions via wire cutting device. The surface of samples has been produced by polishing and grinding processes to get appropriate flat surface for joining. The joining surface of the AA2014 samples has been grinded by employing diverse sets of $(\mathrm{SiC})$ paper thereafter polished by means of diamond paste $0.3 \mu \mathrm{m}$ grain size. Surface roughness portable device has been used to measure the roughness of surface after grinding and polishing. The amount of the surface roughness of the wholly samples is $(0.5 \mu \mathrm{m})$. Cleaning the specimens with acetone was done by using ultrasonic bath device for $15 \mathrm{~min}$ to remove any contaminations adhering on it. The copper powders interlayer with $0.158 \mathrm{~g}$ weights, according to the mass equation of $100 \mu \mathrm{m}$ thicknesses and density of powder, was place on surface of sample and sprinkled by alcohol to hold the powder.

\subsection{Diffusion Ponding Process}

The polished and chemically prepared specimens of a similar AA2014 aluminum alloys were stacked in a holder and fixture shown in Figure 1, and the complete diffusion joining die setup, shown in Figure 2, and its inserted into a vacuum chamber. The whole diffusion bonding system is shown in Figure 3. It involves

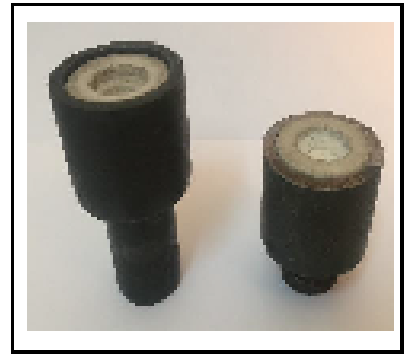

Figure 1. Holder and fixture.

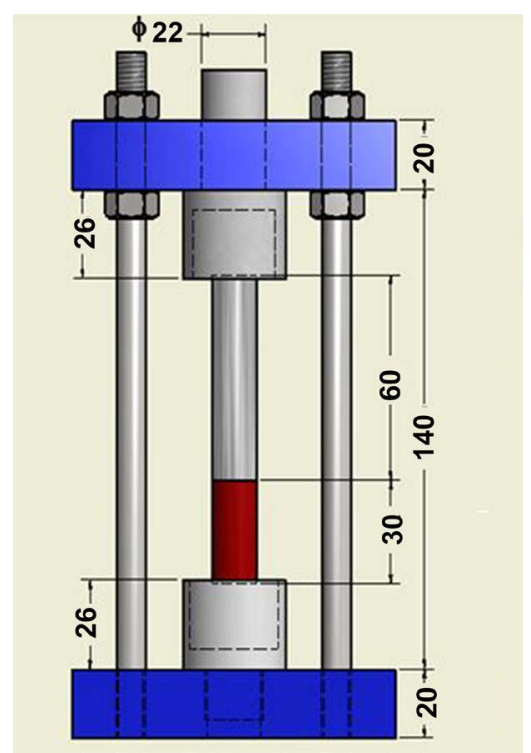

Figure 2. Diffusion bonding die. 


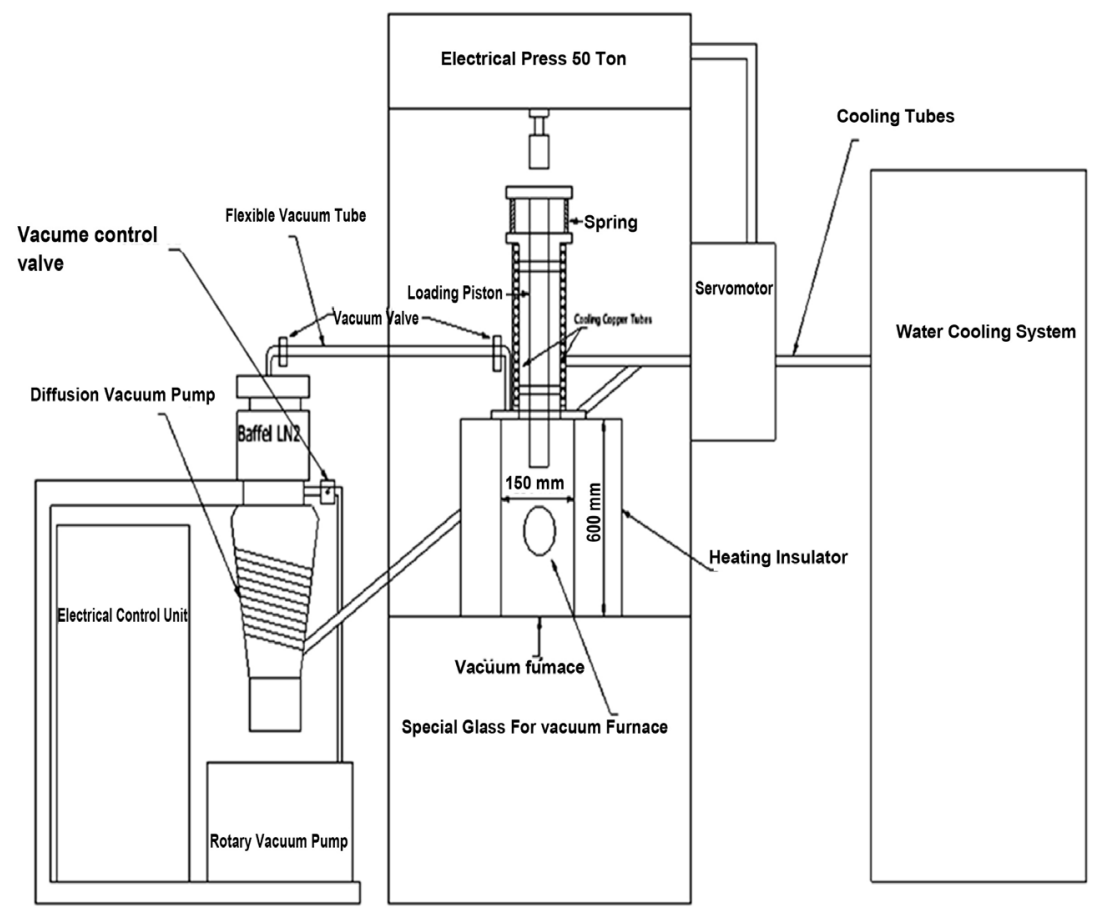

Figure 3. The representation drawing of the diffusion bonding system.

of diffusion vacuum pump, vacuum tube furnace, rotary vacuum pump, cooling and heating system, control and loading unit. The practical load used for joining the samples by means of hydraulic kind (mega-Spanish) of size 50 ton that has servo motor, it should be noted that (each 1 ton is equivalent to $56 \mathrm{MPa}$ according to cross section area of $176.6 \mathrm{~mm}^{2}$ of sample in this work).

The bonding process was conducted at $325,375,425,475^{\circ} \mathrm{C}$ under a vacuum of $1 \times 10^{5} \mathrm{~m}$ bar and holding pressure of $4 \mathrm{MPa}$ for constant period (one hour). Tensile strength test has been carried out for the bonded specimens.

\subsection{Tests}

Diffusion bonding samples have been prepared thru wire cut apparatus into flat tensile test samples as stated by (ASTM E8-8) [6]. The tensile strength examination has been carried out by using tensile test apparatus kind (WDW-200E). The yield strength and the ultimate tensile strength are gained from this test. Micro hardness test of the bonded joint has been performed. The test has been performed by using digital Vickers micro hardness testing device type of (HV-1000B). A load of $200 \mathrm{~g}$ has been applied for holding time of 30 seconds. Optical and scanning electron microscope have been used to perform to examine the microstructure. The sample of the best conditions is cut by wire cutting machine. The specimens are grinded, polished and etching by immersing the samples in etchant solution $\left(\mathrm{HCl}, \mathrm{HNO}_{3}, \mathrm{Hf}, \mathrm{H}_{2} \mathrm{O}\right)$ and washing by water for 2 min and cleaning by acetone thereafter drying in hot air. Diffusion region microstructure has been examined by optical microscope subsequently by scanning electron microscope category (Tescan) with EDS. The Energy Dispersive Spectroscopy test has 
been carried out by using Energy Dispersive Spectroscopy type oxford at the bonding joint. The test has been performed for element analysis by line and point EDS to show element diffusion and depth of diffusion. The XRD examination of specimen has been performed by means of XRD device kind (Shimadzu-6000XRD) XRD outcomes are equated with standard chart.

\section{Results and Discussion}

To examine the mechanical properties of the bonded specimens, uniaxial tension checks were achieved. Table 3 displays the results of tensile properties of the bonded specimens with $\mathrm{Cu}$ interlayers and without interlayer.

From Table 3, wholly tensile test samples for $\mathrm{Cu}$ interlayer, fracture happened at base metal. This denotes that strength at bonding area is greater bonded zone due to high vacuum atmosphere and good surface roughness of samples with decent conditions which drove to diffusion of $\mathrm{Cu}$ powder in the direction of base metal. The superior outcomes have been got when utilizing $\mathrm{Cu}$ powder as interlayer with (187.05 - 188.36) MPa tensile strength. The maximum ultimate tensile strength is $188.36 \mathrm{MPa}$ at $475^{\circ} \mathrm{C}$. The strength for joint bonded in the absence of interlayer grants good outcomes and the extent of tensile strength was (118.55 150.4) MPa.

\subsection{Effect of Temperature on Joining Strength}

The influence of temperature on joining strength with and without using interlayer is clarified in Figure 4. The maximum bonding strength with and without interlayer is $188.39 \mathrm{MPa}$ and $150.4 \mathrm{MPa}$ respectively at $475^{\circ} \mathrm{C}$ and pressure of 4 $\mathrm{MPa}$. The plot shows the best bonding condition was obtained to be with interlayer.

Microhardness examination has been achieved for the testing sample diffusion bonding joint. The microhardness was computed at base metal and bonding area. The examination starts from the left side to the right side of the base metal passing through the interlayer with $0.2 \mathrm{~mm}$ spaced points. Figure 5 represents

Table 3. Results of tensile strength of diffusion bonding specimens.

\begin{tabular}{cccccc}
\hline Experimental No. & Interlayer & $\begin{array}{c}\text { Bonding } \\
\mathrm{T}\left({ }^{\circ} \mathrm{C}\right)\end{array}$ & $\begin{array}{c}\text { Bonding } \\
\mathrm{P}(\mathrm{MPa})\end{array}$ & Fracture location & $\begin{array}{c}\text { Ultimate } \\
\text { strength }(\mathrm{MPa})\end{array}$ \\
\hline 1 & None & 325 & 4 & At interface & 118.55 \\
2 & None & 375 & 4 & At base metal & 129.17 \\
3 & None & 425 & 4 & At interface & 139.74 \\
4 & None & 475 & 4 & At interface & 150.40 \\
5 & Copper powder & 325 & 4 & At base metal & 187.05 \\
6 & Copper powder & 375 & 4 & At base metal & 187.49 \\
7 & Copper powder & 425 & 4 & At base metal & 187.93 \\
8 & Copper powder & 475 & 4 & At base metal & 188.36 \\
\hline
\end{tabular}




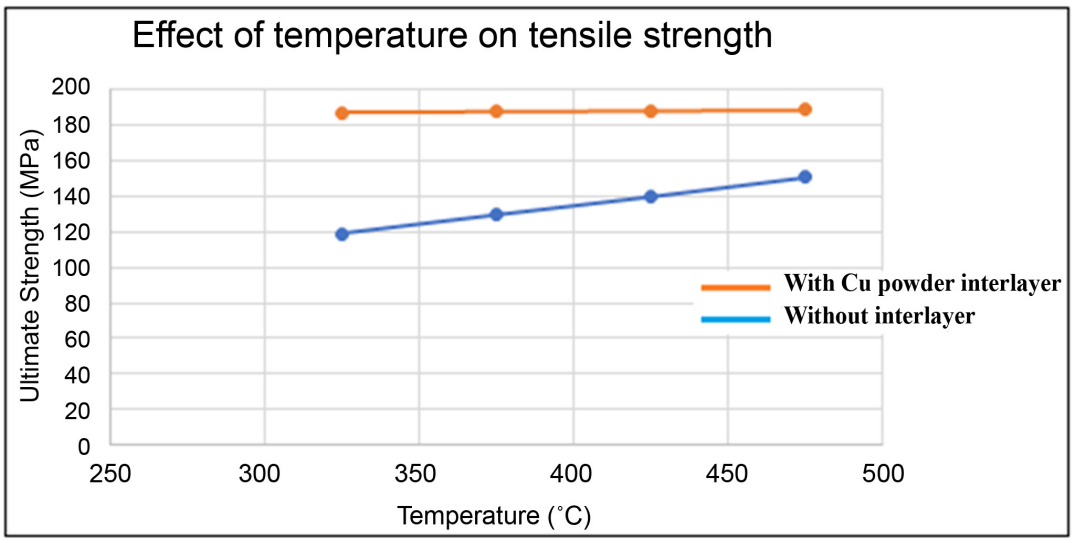

Figure 4. Effect of temperature on joining strength.

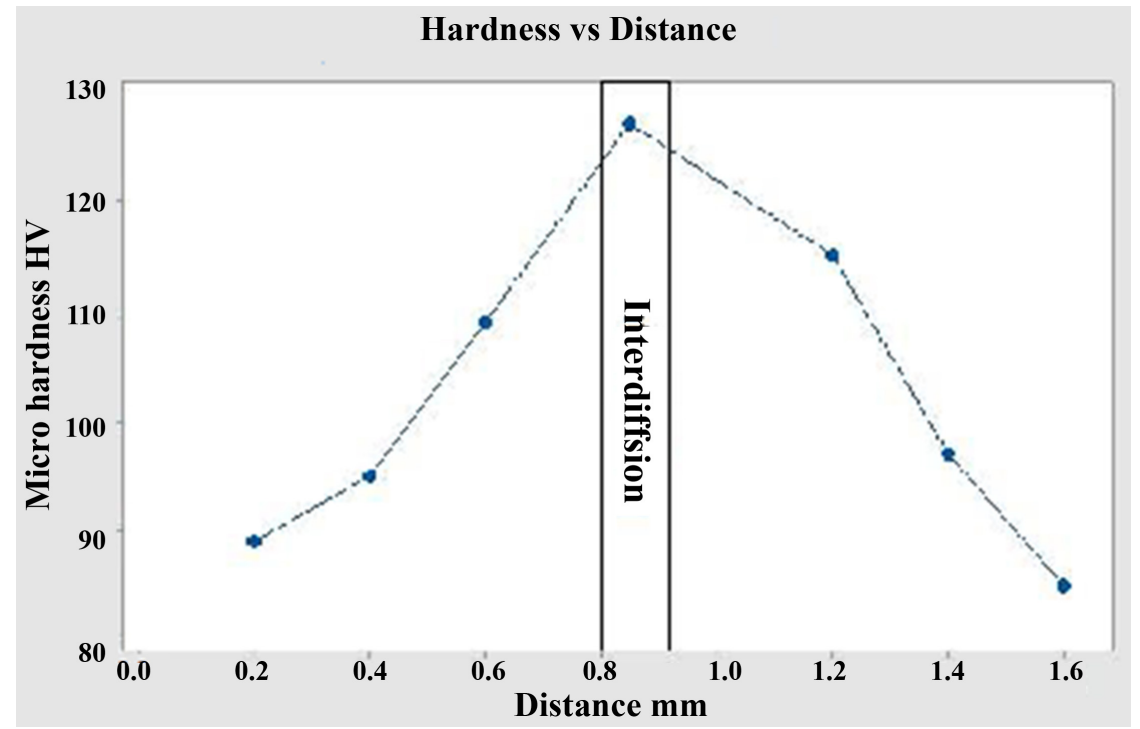

Figure 5. Hardness of the optimum bonding condition.

the microhardness at the best conditions; the microhardness measured recorded $(89 \mathrm{Hv})$ at base metal and enlarged progressively up to $(109 \mathrm{Hv})$ nearby the interlayer. The microhardness measurement is $(127 \mathrm{Hv})$ at interlayer which is superior than of base metal inasmuch as the interlayer is pure powder of copper and has higher hardness than the base metal. Thereafter, the microhardness thru the interlayer in the direction of the base metal on the right of bonding region commenced to reduce. The measurements were $(97 \mathrm{Hv})$ and reduce to $(85 \mathrm{Hv})$ at base metal. The cause for this difference was owing to the high hardness of the $\mathrm{Cu}$ powder that was greater than other areas.

\subsection{Microstructure Test of Diffusion Bonding Joint}

$\mathrm{OM}$ and SEM are utilized for the valuation of the microstructure of diffusion bonding joint achieved at $425^{\circ} \mathrm{C}$, and $4 \mathrm{MPa}$ thrua period of one hour using $\mathrm{Cu}$ powder interlayer. Figure 6 and Figure 7 display the microstructure of the diffusion bonding joint of AA2014 using OM and SEM respectively. 


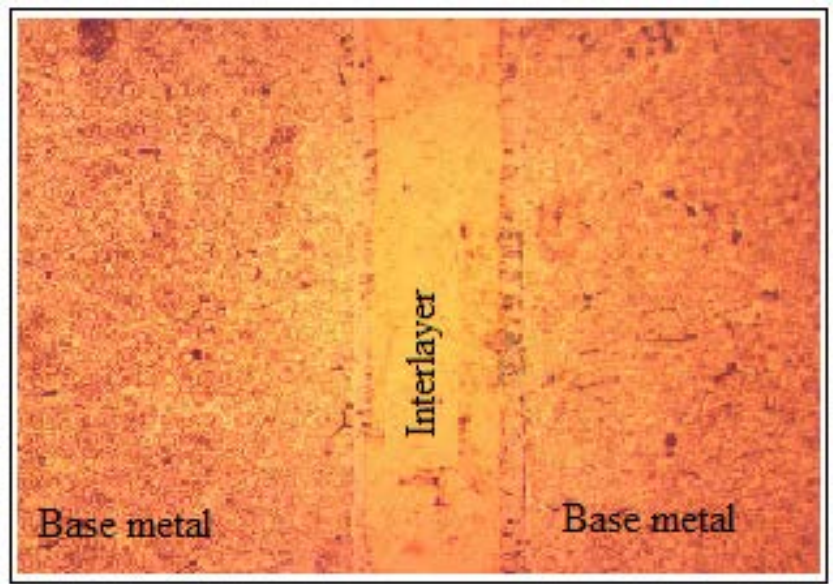

Figure 6. Optical microscope of bonded joints.

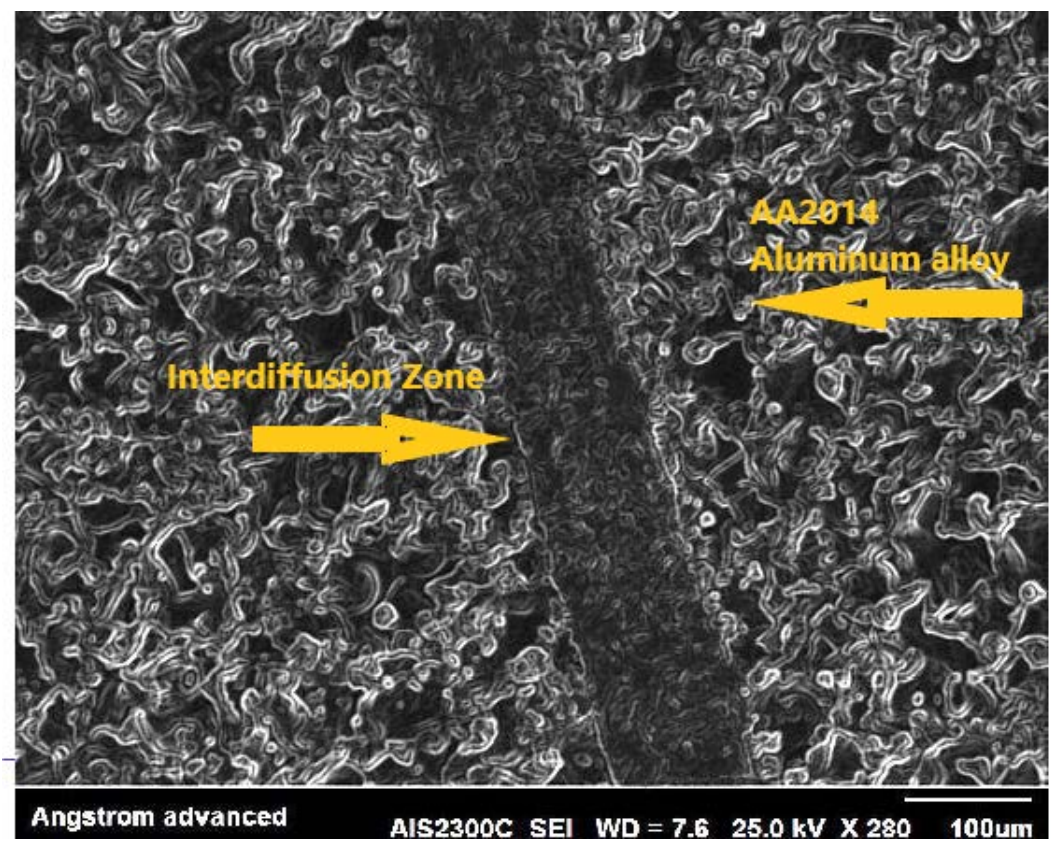

Figure 7. Scanning electron microscope of bonded joints.

The significant factors for diffusion atoms in the diffusion bonding procedures were diffusion coefficient, sufficient time, pressure and temperature applied. The diffusion process needs appropriate time to happen and when the atoms are large further time is required to get a homogenous structure [7]. SEM examination strong minded the structure, phase distribution and diffusion depth. Figure 8 displays the microstructure of best bonding joint regions with powder $\mathrm{Cu}$ interlayer. The maximum bonding strength was $188.36 \mathrm{MPa}$ noted at maximum temperature. The combinations effect of temperature and pressure appeared at maximum temperature of $475^{\circ} \mathrm{C}$ due to comprehensive coalescence among two coupling surfaces associated with high diffusion rate.

The diffusion coefficient for copper is equal to $6.54 \mathrm{~m}^{2} \mathrm{~s}^{-1} \times 10^{-4}$. The $\mathrm{Cu}$ interlayer exposed the supreme tensile strength inasmuch as the upsurge in the 


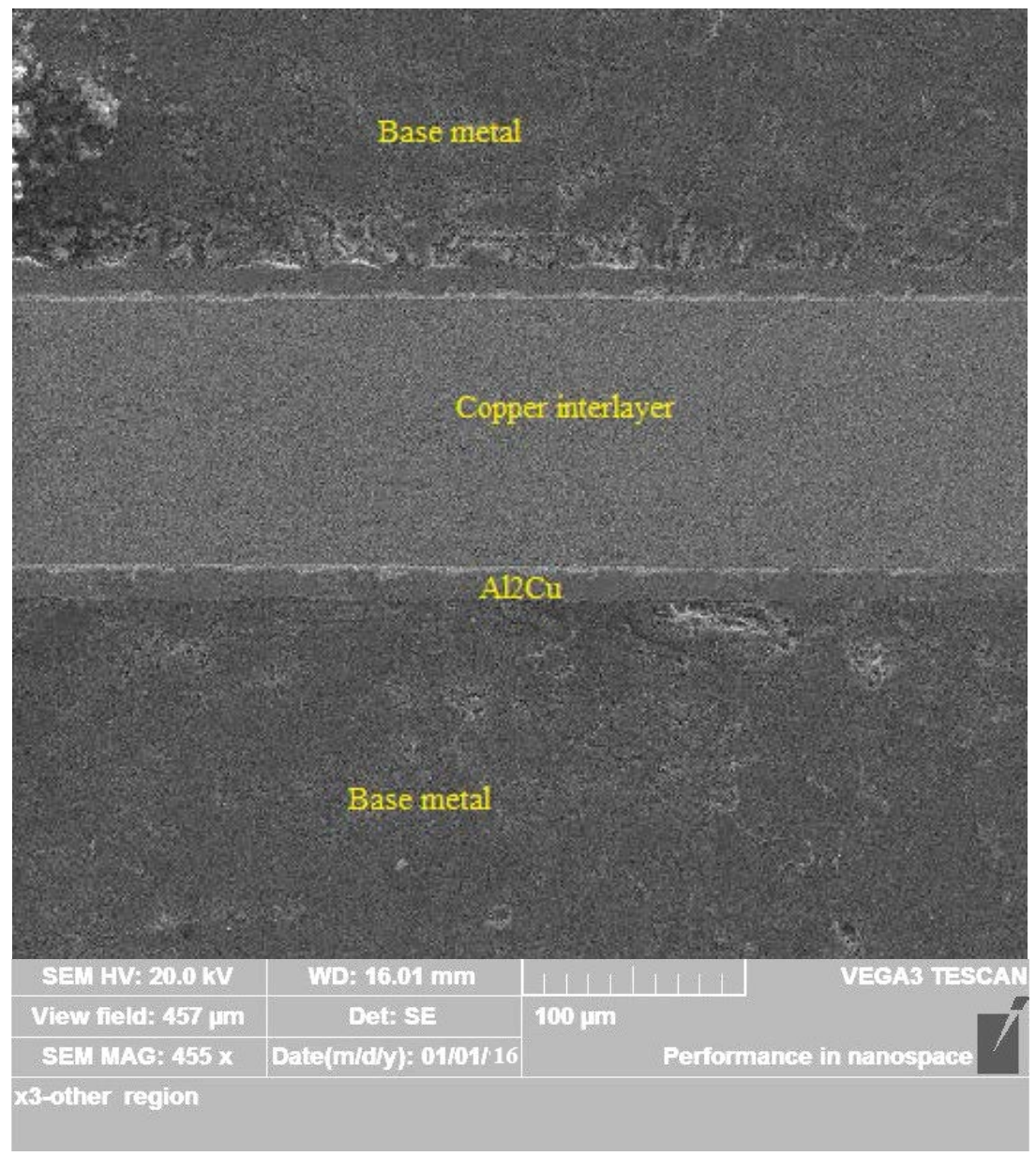

Figure 8. SEM of joint bonded at $475^{\circ} \mathrm{C}$ and $4 \mathrm{MPa}$.

creating of $\mathrm{Al}_{2} \mathrm{Cu}$ phase which grants the improvement of mechanical properties [8]. Rising temperature extent bellow the temperature of annealing will improve the mechanical properties especially tensile strength of the welded joint to be superior than the analogous joint welding. Raising the temperature directly above $475^{\circ} \mathrm{C}$ gave rise to fast grain growth which drove to a reduction in joining strength. Pressure is not extremely effective likened with other factors, the rise in pressure some more than increase temperature leads to plastic deformation and is not to get intact joint [9].

The bonded joint was tested using EDS at diverse points is exposed in Figure 9, which displayed the chemical composition of elements at the specific points. Point 1 represented the composition of the $\mathrm{Cu}$ powder and other points $(2,3,4$ and 5) indicated to diffusion of $\mathrm{Cu}$ into $\mathrm{AA} 2014 \mathrm{Al}$ alloy. Table 4 represents the chemical composition of elements at separately point.

The EDS line for best conditions joint regions has been inspected as shown in Figure 10. The diffusion of $\mathrm{Cu}$ atoms in the direction of base metal on both side of interdiffusion area is revealed obviously. The diffusion of $\mathrm{Cu}$ atoms is high from interlayer and declines progressively in the direction of base metal. The no segregation of elements and good intimate contact at diffusion regions give rise 

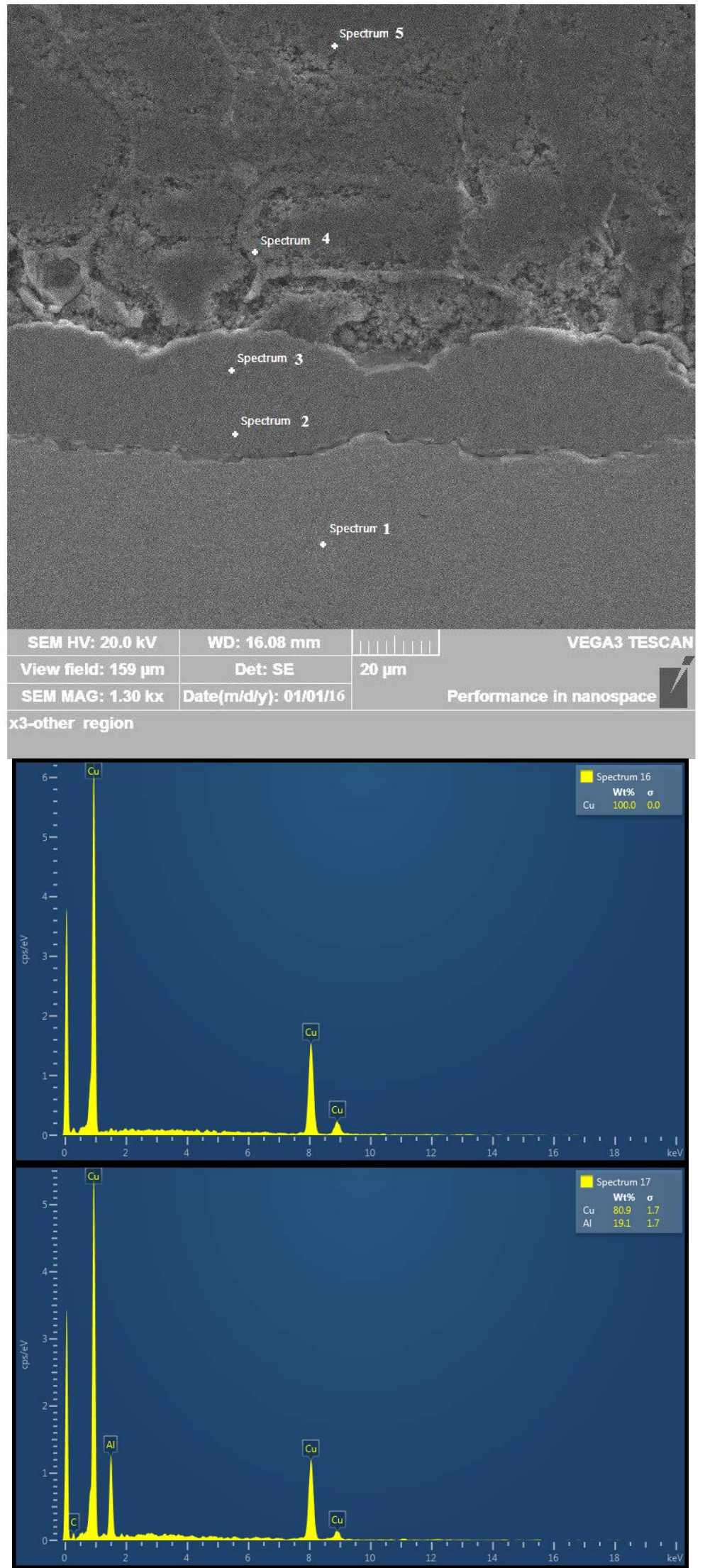

Figure 9. EDS analysis of points. 
Table 4. The chemical composition investigation by EDS.

\begin{tabular}{cccc}
\hline Points & $\mathrm{Al}$ & $\mathrm{Cu}$ & $\mathrm{Mg}$ \\
\hline 1 & 0 & 100 & 0 \\
2 & 19.1 & 80.9 & 0 \\
3 & 49.1 & 50.9 & 0 \\
4 & 86.7 & 12.3 & 1 \\
5 & 94.3 & 4.6 & 1.1 \\
\hline
\end{tabular}
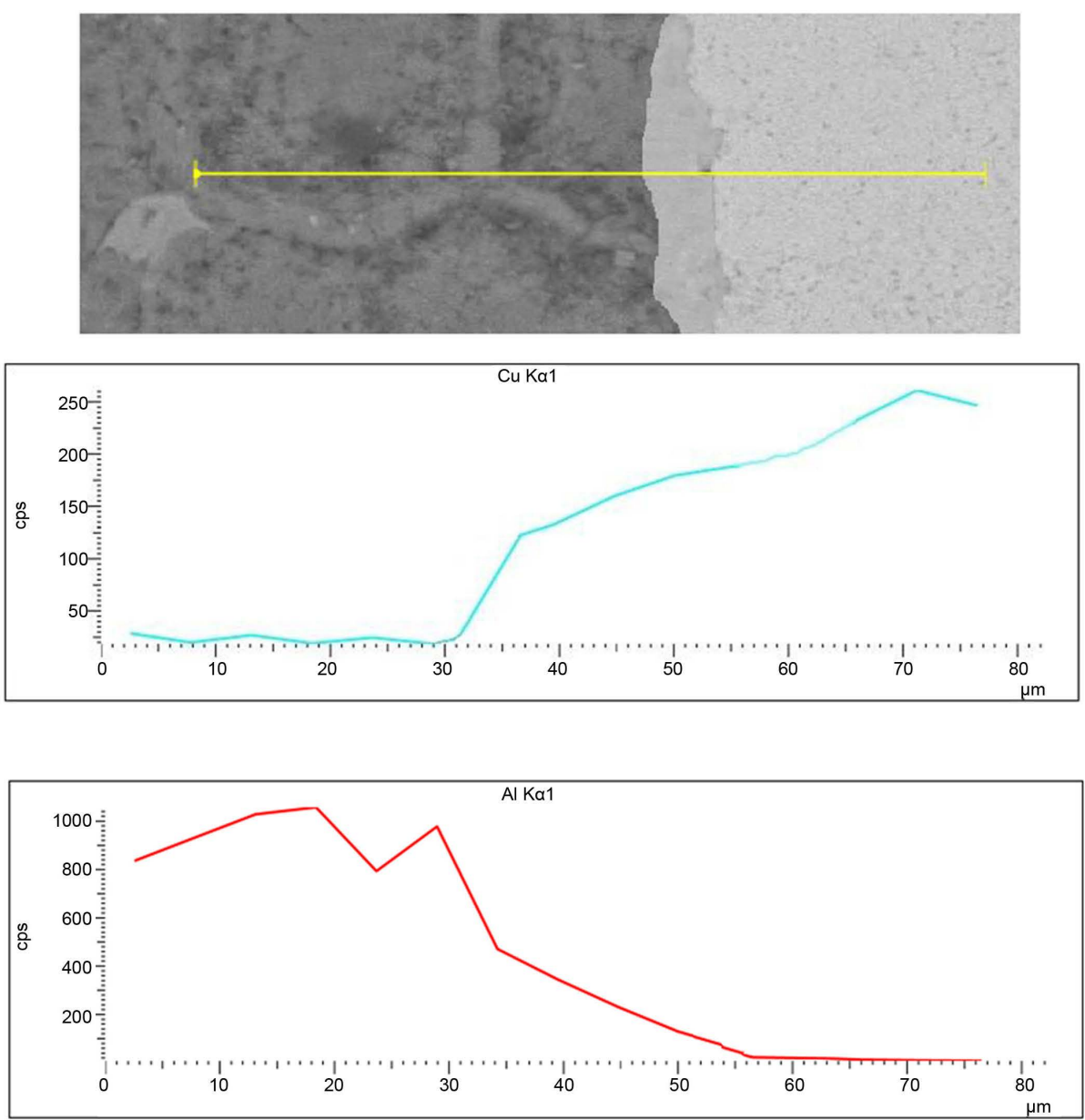

Figure 10. EDS line on left side interdiffusion.

to in perfect bonding. The extreme deepness of diffusion of $\mathrm{Cu}$ atoms in the direction of base metal on both sides of diffusion region is nearly $19.1 \mu \mathrm{m}$. The diffusion deepness is elevated because the high free energy of the powder body, unstable and accompanying with existence of actual large internal interface [10].

In Figure 11 the XRD examination of the best conditions (pressure bonding 4 $\mathrm{Mpa}$, temperature bonding of $475^{\circ} \mathrm{C}$ and holding time is one hour) with pure powder $\mathrm{Cu}$ as the interlayer is existing. Three phases of $\mathrm{Al}, \mathrm{Cu}$ and $\mathrm{Al}_{2} \mathrm{Cu}$ are determined. The higher diffusion coefficient of $\mathrm{Cu}$ than $\mathrm{Al}$ make the immigration of $\mathrm{Cu}$ atoms in the direction of $\mathrm{Al}$ is easier than the opposite. The powder 


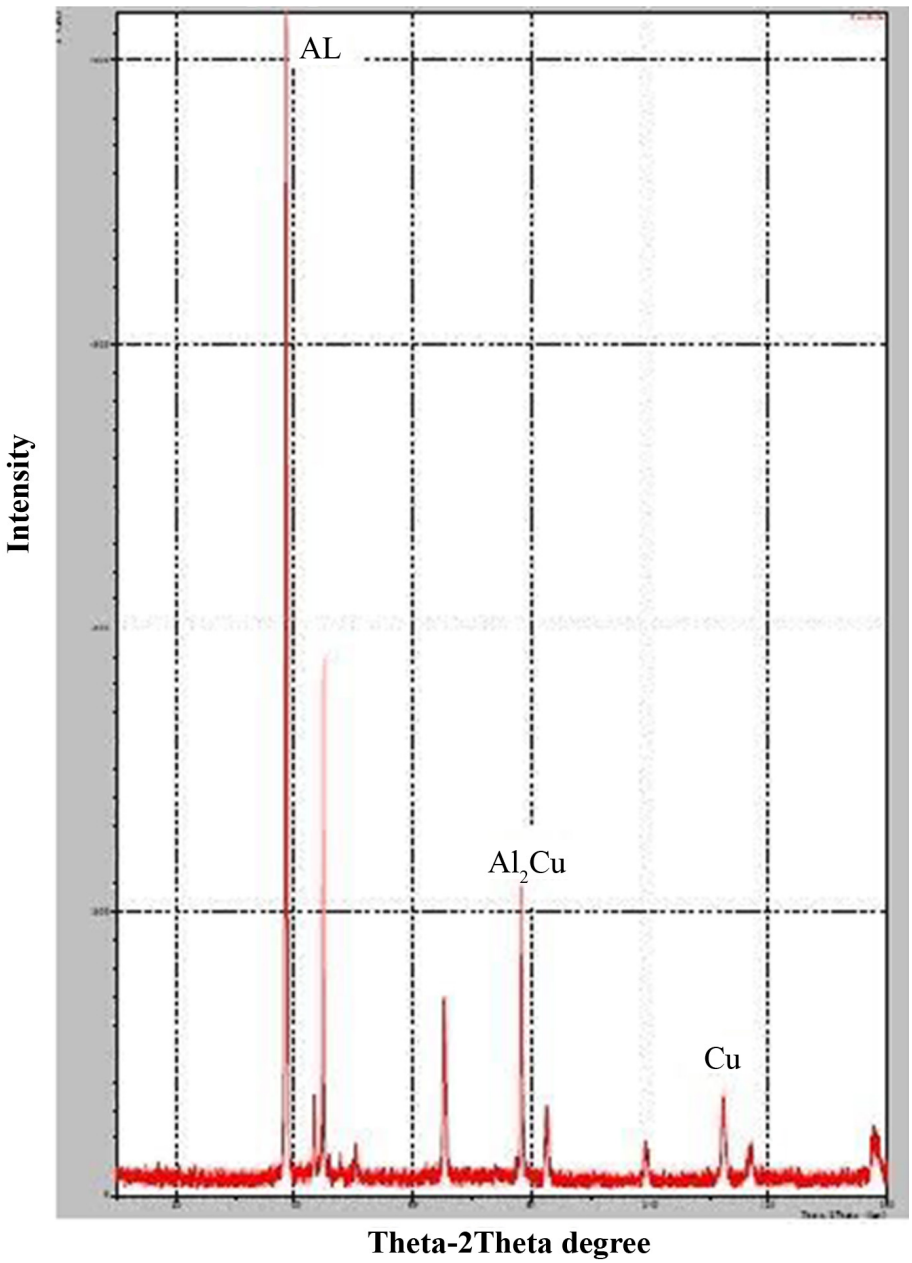

Figure 11. XRD examination of optimum bonding joint.

particles of copper diffused into $\mathrm{Al}$ alloy caused an upsurge in mechanical properties and intimate contact among the same alloy this was as a consequence of the increased creation of phases percentage of $\mathrm{Al}_{2} \mathrm{Cu}$ [11].

\section{Conclusions}

1) Bonding joint of aluminum alloy AA2014 with powder interlayer of $\mathrm{Cu}$ powder is better than without ones.

2) The best bonding conditions of diffusion bonding process are as pressure of $4 \mathrm{MPa}$, temperature of $475^{\circ} \mathrm{C}$ and bonding duration one hour. This condition resulted in tensile strength of $188.36 \mathrm{MPa}$.

3) The microhardness of the diffusion zone is more than of base metal since the hardness of copper is higher than of aluminum alloy AA2014.

4) Maximum deepness of diffusion of copper powder into aluminum alloy AA2014 was about $19.1 \mu \mathrm{m}$.

\section{Acknowledgements}

The authors express their gratitude to Mustansiriyah University, College of En- 
gineering, Department of Materials Engineering (Mustansiriyah.edu.iq) Iraq, Baghdad for its support in the preparation this paper.

\section{Conflicts of Interest}

The author declares no conflicts of interest regarding the publication of this paper.

\section{References}

[1] Saleh, A.A. (2018) Effect of Heat Treatment on the Mechanical Properties of AA2014 Alloy. Contemporary Engineering Sciences, 11, 3409-3419. https://doi.org/10.12988/ces.2018.87345

[2] Mahendiran, G., Balasubramanian, V. and Sethilvelan, T. (2011) Mechanical and Metallurgical Properties of Diffusion Bonded AA2024 Aluminum Alloy and Commercial Grade Copper. Mechanical Engineering, 38, 4283-4289.

[3] ASM International (1993) Metals Handbook: Welding Brazing and Soldering. Vol. 6, American Society for Metals, Metals Park.

[4] Akac, E. and Gursel, A. (2015) The Importance of Interlayer in Diffusion Welding-A Review. Periodicals of Engineering and Natural Science, 3, 12-16.

[5] Mahendiran, G., Balasubramanian, V. and Sethilvelan, T. (2010) Influences of Diffusion Bonding Process Parameters on Bond Characteristics of $\mathrm{Mg}-\mathrm{Cu}$ Dissimilar Joints. Transactions of Nonferrous Metals Society of China, 20, 997-1005. https://doi.org/10.1016/S1003-6326(09)60248-X

[6] ASTM International, B209M-14, Standard Specification for Aluminum and Aluminum-Alloy Sheet and Plate (Metric).

[7] Balasubramanian, M. (2015) Application of Box-Behbken Design for Fabrication of Titanium Alloy and 304 Stainless Steel Joints with Silver Interlayer by Diffusion Bonding. Materials and Design, 77, 161-169. https://doi.org/10.1016/j.matdes.2015.04.003

[8] Gao, Y., Mo, Q., Luo, Z., Zhand, L. and Huang, C. (2006) Atomic Bonding and Properties of Al-Cu Alloy with $\theta\left(\mathrm{Al}_{2} \mathrm{Cu}\right)$. Journal of Electronic Materials, 35, 1801-1805. https://doi.org/10.1007/s11664-006-0160-7

[9] Pilling, J. and Ridley, N. (1987) Solid State Bonding of Superplastic AA 7475. Materials Science and Technology, 3, 353-359. https://doi.org/10.1179/026708387790122666

[10] Lyushinskii, A.V. (2009) Criteria for Selecting Interlayers in Diffusion Bonding Dissimilar Metals. Welding International, 15, 830-832.

[11] Dolgopolov, N.A., Rodin, A.O., Simanov, A.V. and Gontar, I.G. (2009) Diffusion of Copper along Grain Boundaries in Aluminum. Non-Ferrous Metals, 50, 133-137. https://doi.org/10.3103/S1067821209020114 